Tạp chí Khoa học và Công nghệ biển T11 (2011). Số 1. Tr 15 - 30

\title{
TỐC Độ CHUYỂN ĐỘNG KIẾN TẠO HIỆN ĐẠI TRÊN BIỂN ĐÔNG VÀ KHU VỰC LẦ CẬN THEO CHU KỲ ĐO GPS 2007 - 2009
}

\author{
PHAN TRỌNG TRỊNH, NGÔ VĂN LIÊM, TRÀ̀N ĐÌNH TÔ, VY QUỐC HẢI, \\ NGUYẼ̃N VĂN HƯỚNG, HOÀNG QUANG VINH, BÙI VĂN THOOM, NGUYẼ̃N QUANG XUYÊN, \\ NGUYẼ̃N VIÊT THUẬN, BÙI THỊ THẢO \\ Viện Địa chất, Viện Khoa học và Công nghệ Việt Nam
}

\author{
LÊE HUY MINH
}

Viện Vật lý Địa cầu, Viện Khoa học và Công nghệ Việt Nam

\author{
JOHN BEAVAN
}

Viện Khoa học Địa chất và Hạt nhân, New Zealand

Tóm tắt: Bài báo trình bày nhũng tốc độ chuyển dịch kiến tạo hiện đại trên khu vực Biển Đông và khu vưc lân cận nhò̀ phân tích đo lạp GPS của đề tài KC09.11/06-10, KC09.11BS/06-10 và tổng hơp số liệu của nhiều tác giả trong khoảng thời gian 1994 - 2009. Đáng luu ý là các đề án GEODYSSEA, Trung Quốc, Tổ chức Trắc địa các nước Châu Á - Thái Bình Dương và các kết quả đo khu vục ở Philipine, Indonesia, Thái Lan, Đài loan. Các trạm đo GPS Láng (LANG), Bạch Long Vĩ (BLV1), Song Tủ Tây (STT1), Côn Đảo (CDA1), Huế (HUES), Đồng Hới (DOHO), Hồ Chi Minh (HOCM) đã được liên kết các trạm đo GPS trong hệ thống đo IGS Quốc tế là COCO,BAKO, NTUS, PIMO, KUNM và WUHN. Chúng tôi đã xác định chuyển dịch và tốc độ chuyển dịch tuyệt đối của các điểm trong hệ toạ độ toàn cầu IGSO5. Kết quả nhận được trạm LANG chuyển dịch về phía Đông với tốc độ $39 \mathrm{~mm} /$ năm, chuyển dịch về phía Nam với tốc độ 13 $\mathrm{mm} / \mathrm{năm}$. Tốc độ chuyển dịch của trạm BLV1 về phía Đông là $29 \mathrm{~mm} / \mathrm{năm}$ đồng thời chuyển dịch về phía Nam với tốc độ $14 \mathrm{~mm} /$ năm. Trạm STT1 chuyển dịch về phía Đông với tốc độ 22,5 $\mathrm{mm} / \mathrm{năm}$ và chuyển dịch về phía Nam vói tốc độ $10,5 \mathrm{~mm} / \mathrm{năm}$. Tốc độ chuyển dịch về phía Đông của trạm CDA1 21 mm/năm và chuyển dịch về phía Nam $10 \mathrm{~mm} /$ năm. Tốc độ chuyển dịch về phía Đông của trạm DOHO là $26,8 \mathrm{~mm} /$ năm và chuyển dịch về phía Nam là $~ 9 \mathrm{~mm} /$ năm. Tốc độ chuyển dịch về phía Đông của trạm HUES $30 \mathrm{~mm} / n a ̆ m$ và chuyển dịch theo huóng Nam 20mm/năm. Tốc độ chuyển dịch về phía Đông của trạm HOCM 21,5 mm/năm và chuyển dịch theo huóng Nam $\sim 12 \mathrm{~mm} / \mathrm{năm}$.

\section{MỞ ĐÀ̀U}

Biển Đông được xem là biển rìa thuộc vành đai Tây Thái Bình Dương. Rìa Đông 
của Biển Đông khá phức tạp với hai đới hút chìm cắm ngược hướng, trong đó đới hút chìm chạy dọc máng Manilla có hướng cắm về phía Đông trong khi một đới hút chìm khác chạy dọc rìa Đông Philipin có hướng cắm về phía Tây. Về phía Nam, mảng Ấn - Úc hiện đang cắm xuống mảng Âu - Á dọc theo đới hút chìm Sunda với tốc độ $6-7 \mathrm{~cm} / \mathrm{năm}$. Phân bố chấn tiêu động đất chính và dư chấn theo mặt cắt cũng phản ánh hưởng cắm của mảng Ấn - Úc chúi xuống dưới mảng Âu - Á. Những trận động đất lớn nhất trên Thế giới thường xảy ra tại ranh giới hội tụ của hai mảng, nơi có sự xiết ép mạnh mẽ. Trong 10 trận động đất lớn nhất trong thời gian gần đây, 9 trận động đất trước đều gắn liền với hoạt động xiết ép của đới hút chìm ở rìa biển Thái Bình Dương. Trận động đất tại Sumatra cũng không ngoại lệ và liên quan đới hoạt động xiết ép của đới hút chìm Sunda giữa mảng Ấn Úc và mảng Âu - Á. Phần lớn vùng Đông Nam Á hiện nay gồm Việt Nam, Lào, Campuchia, Thái lan, bán đảo Malaisia, Sumatra, Borneo, Java và hầu như toàn bộ Biển Đông được bao quanh bởi các đới cuốn chìm, gồm mảng Philipin, mảng Úc, mảng Ấn độ được xếp vào khối Sunda. Về phía Bắc khối Sunda bị bao bởi phần Đông Nam của đới đụng độ Ân Độ - Âu Á và Nam Trung Hoa. Hầu hết các trận động đất đều phân bố trong đới cuốn chìm và đới đụng độ. Bên trong đới Sunda chỉ có những trận động đất yếu và độ sâu chấn tiêu rất nông. Điều đó cho thấy khối Sunda tồn tại như một khối thạch quyển cứng, mặc dù nguồn gốc địa chất của nó không đồng nhất.

Trải qua 3 thập kỷ, nhiều mô hình về biến dạng thạch quyển đã được đề xuất. Có thể chia ra 2 luận điểm chính. Luận điểm thứ nhất, cho rằng biến dạng thạch quyển tuân theo qui luật chảy nhớt trong môi trường liên tục (England, Houseman, 1986). Luận điểm thứ 2 là chuyển dịch của khối thạch quyển cứng dọc theo các đới đứt gãy hẹp (Tapponnier và nnk., 1982). Việc xác định chính xác chuyển dịch cho phép hiểu rõ hơn các mô hình này hoặc cho phép hiệu chỉnh các mô hình trên.

Trước đây, khối Sunda thường được xem là phần mở rộng của mảng Châu Á. Tuy nhiên những nghiên cứu địa chất và địa vật lý ở bán đảo Indonesia cho thấy Đông nam Á chuyển dịch khác hẳn mảng Âu Á. Khẳng định những quan sát đó chỉ trở thành hiện thực nhờ tiến bộ quan trọng trong trắc địa vũ trụ, kể từ năm 1990. Sử dụng độ chính xác cao của GPS cho phép xác định chính xác chuyển dịch của vỏ trái đất. Mạng đo địa động lực của Nam và Đông Nam Á (GEODYSSEA) với gần 40 trạm phân bố trên toàn Đông Nam Á, khẳng định Sunda là một khối gắn kết, chuyển dịch so với mảng Âu - Á và tách biệt với nền Siberi qua một loạt các khối biến dạng và chuyển dịch (Wilson và nnk. 1998). Mặc dù tất cả các trạm đo GPS với xấp xỉ bậc nhất cho thấy Đông Nam Á chuyển dịch về phía Đông cỡ $1 \mathrm{~cm} /$ năm so với nền Siberi, vẫn có sự khác biệt đáng kể về phân định ranh giới của khối Sunda so với mảng Âu Á và khối Nam Trung Hoa. Từ năm 1998, mạng đo GPS ở Đông Nam Á đã được mở rộng đáng kể cả đo theo các đợt đo và trạm ghi liên tục. Điều 
đó được thực hiện với sự tham gia của các cơ quan trắc địa các địa phương « Đông Nam Á: Nghiên cứu môi trường với công nghệ trắc địa vũ trụ» (SEAMERGES), hợp tác giữa Châu Âu, Indonesia, Nhật, Malaisia, Thái Lan. Kết quả nghiên cứu này giúp mở rộng thời gian đo trong 1 thập kỷ với gần 100 điểm đo. Tất cả các số đo đã được xử lý trên thành tựu mới nhất về công nghệ sử lý GPS để xác định được tốc độ chuyển dịch trên hệ thống toạ độ Quốc tế ITRF2000. Kể từ 1994, các số đo GPS kéo dài trong 10 năm theo từng đợt đo. Tốc độ chuyển dịch của các trạm tạo thành đường tuyên tính minh chứng chuyển dịch ổn định. Điều này có thể kiểm chứng nhờ phân tích độ sai lệch so với đường tuyến tính. Hầu như chỉ quan sát thấy sai lệch nhỏ trên cả 3 chiều. Phương sai lần lượt là 3,5 và 11 mm theo phương Bắc-Nam, Đông-Tây và thẳng đứng. Ở một số trạm, dạng tuyến tính không được trơn, đó là các vùng có chế độ địa chấn cao như Sulawesi và cung đảo Banda. Một số trạm có đường thẳng trơn, không có các sự kiện động đất, ở một số trạm chịu tác động của động đất. Trong mạng, những điểm chịu tác động của động đất bị loại trừ và sự nhảy vị trí đã được xác định (với các trạm đo liên tục).

Trong bài viết này, chúng tôi trình bày kết quả mới đo GPS ba chu kỳ 2007-20082009 trên Biển Đông, đồng thời tổng hợp các kết quả nghiên cứu trước đây của các tác giả khác nhau về chuyển dịch kiến tạo hiện đại có tính tới kết quả mới nhất đo chuyển dịch kiến tạo hiện đại trong khuôn khổ đề tài trọng điểm KC09.11/06-10 và KC09.11BS.06-10. Với mục đích chính làm sáng tỏ quá trình chuyển dịch kiến tạo hiện đại trên Biển Đông, bài viết còn đánh giá mức độ biến dạng của của đới đứt gãy Manilla, đứt gãy Bắc Borneo, đứt gãy rìa tây Biển Đông (kinh tuyến 110), là những đứt gãy có khả năng sinh chấn cao nhất trên Biển Đông.

\section{KẾT QUẢ XÁC ĐỊNH TỐC Độ CHUYỂN DỊCH KIẾN TẠO HIỆN ĐẠI TRÊN BIỂN ĐÔNG}

Để xác định được tốc độ chuyển dịch kiến tạo hiện đại, các phương pháp trắc địa truyền thống từng được sử dụng như phương pháp đo thuỷ chuẩn và phương pháp tam giác đạc. Trong qui mô nhỏ các phương pháp trên có độ chính xác cao nhưng tỏ ra hạn chế trên một qui mô rộng lớn. Để liên kết trên diện rộng các phương pháp trắc địa không gian như DOPPLER, VLBI (Very Long Baselines Interferencia), định vị toàn cầu GPS đã được áp dụng. Công nghệ GPS, với việc sử dụng các máy thu 2 tần số và các phần mềm xử lý chuyên dụng có kết hợp với các dữ liệu bổ trợ được mô hình hoá như tầng điện ly, tầng đối lưu, mô hình khí quyển, mô hình thuỷ triều, đã giúp các tính toán về vị trí và vận tốc chuyển dịch của vỏ Trái đất đạt tới sai số cỡ milimet trong phạm vi rộng tới hàng ngàn $\mathrm{km}$. Để tính toán với độ chính xác cao các chuyển dịch kiến tạo hiện đại bằng công nghệ 
GPS, các trạm phục vụ GPS quốc tế (International GPS service - IGS ) đã xây dựng, thu và xử lý số liệu liên tục của mạng lưới các trạm IGS trên phạm vi toàn cầu và đã tính được hướng cũng như vận tốc chuyển dịch của các mảng kiến tạo của Trái đất ở nhiều quy mô và mức độ khác nhau với độ chính xác ngày càng cao. Nhờ những số liệu đo liên tục tại các trạm IGS, cũng như các tham số bổ trợ về tốc độ chuyển dịch của các trạm IGS, ta có thể xác định được tốc độ chuyển dịch tuyệt đối của các trạm GPS.

Chúng tôi đã tiến hành đo 3 đợt tại các trạm Láng, Bạch Long Vĩ, Song Tử Tây, Côn Đảo, Đồng Hới, Huế, Hồ Chí Minh trong 3 năm 2007, 2008 và 2009. Tại mỗi đợt đo, chúng tôi đã tiến hành đo liên tục $7 \mathrm{ca}$, mỗi ca 23 giờ 40 phút. Cơ sở dữ liệu được sử dụng trong tính toán này, ngoài dữ liệu của trạm GPS Láng (LANG) (Ngô Văn Liêm, và nnk., 2008), Bạch Long Vĩ (BLV1), Song Tử Tây (STT1), Côn Đảo (CDA1), Huế (HUES), Đồng Hới (DOHO), Hồ Chí Minh (HOCM), chúng tôi sử dụng dữ liệu đo liên tục của 6 trạm IGS (COCO, NTUS, PIMO, BAKO, KUNM, WUHN) làm trạm tham chiếu. Các dữ liệu của tổ chức GPS Quốc tế phục vụ địa động lực (IGS) như lịch vệ tinh chính xác, mô hình tầng điện $1 \mathrm{y}$, các tệp hiệu chỉnh giữa $\mathrm{P} 1-\mathrm{C} 1, \mathrm{P} 1-\mathrm{P} 2$ đối với vệ tinh và máy thu, toạ độ cũng như vận tốc chuyển dịch của các trạm IGS trong hệ quy chiếu toàn cầu IGS05 đã được sử dụng trong tính toán. Khoảng cách gần nhất giữa hai trạm là 223 km (Láng - Bạch Long Vĩ).

Sử dụng hệ toạ độ toàn cầu IGS05, với tốc độ đã biết của các trạm IGS: COCO, NTUS, PIMO, BAKO, KUNM và WUHN, chúng ta có thể tính được chuyển dịch tuyệt đối của các trạm đo. Các kết quả tính theo các phần mềm khác nhau và được 4 nhóm tính toán độc lập được thể hiện ở bảng 1. Với tính toán trên BERNESE 4.2, giả thiết các giá trị chuyển dịch tại các điểm IGS coi như đã biết, sai số coi như bằng không. Nói cách khác trong quá trình tính toán các điểm IGS coi như cố định với tốc độ đã biết. Các chuyển dịch thẳng đứng tại các điểm coi như bằng không. Sai số sẽ dồn hết cho các điểm cần tính như BLV1, LANG, STT1, v. v..

Các tính toán trên GAMIT và trên BERNESE 5.0 của Viện Địa chất (VĐC) và Viện Địa chất và Hạt nhân New Zeland (GNS) đều dàn sai số cho cả các tram IGS và các trạm đo tại Việt Nam. Nói cách khác tại các điểm đo IGS khớp nối với các trạm đo Việt Nam theo "Constraint" chứ không phải khớp cố định (Fixed) (bảng 1). Mỗi điểm đo được lần lượt trình bày kết quả tính theo phần mềm BERNESE 4.2, GAMIT, BERNESE 5.0 do Viện Địa chất và Hạt nhân New Zealand thực hiện (GNS), BERNESE 5.0 do Viện Địa chất-Viện Khoa học và Công nghệ Việt Nam thực hiện (VĐC). Kết quả này có sai lệch nhẹ với kết quả sơ bộ trước đây, có bổ sung thêm số liệu của các trạm Đồng Hới, Huế và Hồ Chí Minh (Phan Trọng Trịnh và nnk., 2009). 


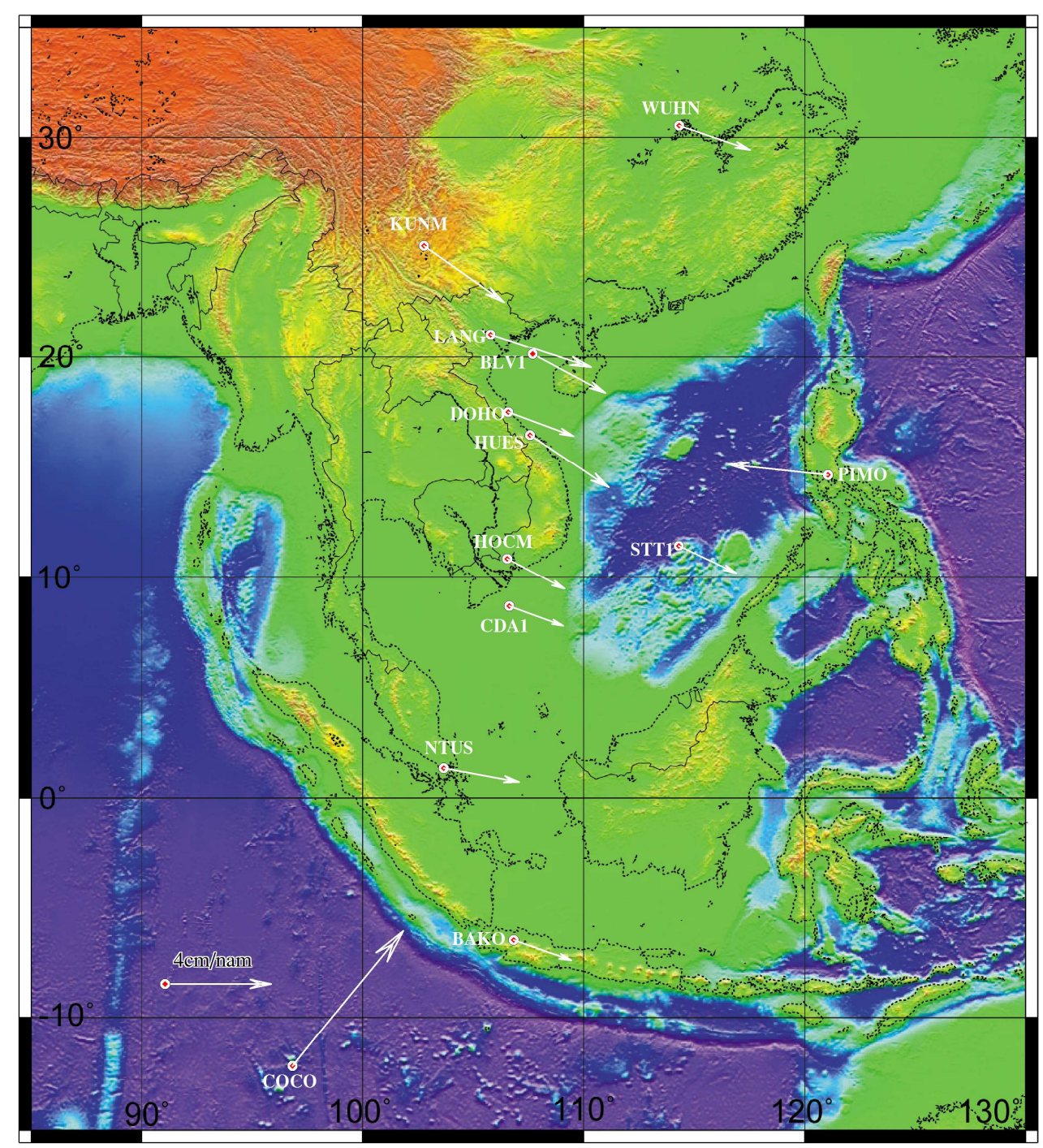

Hình 1: Sơ đồ tốc độ chuyển dịch tuyệt đối trong IGS05 của các trạm GPS trên Biển Đông, theo 3 đợt đo các năm 2007 - 2008 - 2009

\section{CHUYỂN DỊCH KIẾN TẠO HIỆN ĐẠI TRONG KHỐI SUNDA}

Nghiên cứu về khu vực Nam và Đông Nam Châu Á, đề án GEODYSSEA (Geodynamics of South and South - Earth Asia) thông qua 3 chu kỳ đo 1994, 1996 và 1998 đã xác định được tốc độ và hướng chuyển dịch tuyệt đối của vỏ Trái đất trong khu vực này với sai số $4-7 \mathrm{~mm}$ theo chiều ngang và $10 \mathrm{~mm}$ theo theo chiều đứng (Michel và nnk., 2001). Tiếp tục chương trình GEODYSSEA là chương trình hợp tác giữa Châu Âu 
và ASEAN "Southeast Asia: Mastering Environmental Research with Geodetic Space Techniques"' (SEAMERGES) với sự tham gia của các nước Châu Âu với Nhật, Indonesia, Malaysia, Thái Lan với hơn 100 điểm đo, sự mở rộng phạm vi nghiên cứu. Trung Quốc đã thiết lập mạng lưới quan trắc chuyển dịch vỏ trái đất từ 1997 trong chương trình "Crustal Movement Observation Network of China" (CMONOC) với 27 trạm đo liên tục và 1100 điểm đo không liên tục. Các đợt đo 1999, 2001 và 2004 cho thấy biến dạng trên cao nguyên Tây Tạng, các rìa của nó, đới Hymalaya và Altyn Tagh đã hấp thụ $90 \%$ chuyển dịch tương đối giữa mảng Ấn Úc và mảng Châu Á (Zhang và nnk, 2004; Niu và nnk, 2005; Shen và nnk, 2005; Gan và nnk, 2007). Ở rìa Đông của cao nguyên Tây Tạng, chuyển dịch về phía Đông về rìa Tây của Tứ Xuyên trong khi ở bắc Vân Nam, chuyển dịch về Đông Nam trong khi ở Nam Vân Nam chuyển dịch chuyển thành Nam-Đông Nam. Tại mảng Nam Trung Hoa, tốc độ chuyển dịch về phía Đông trong khoảng 6$10 \mathrm{~mm} /$ năm (Zhang và nnk, 2004). Trận động đất xảy ra ở Tứ Xuyên ngày 12 tháng 5 năm 2008 với magnitude 7.9 là kết quả hấp thụ của chuyển dịch về phía Đông qua ranh giới đứt gãy chờm nghịch ở rìa Tây Tứ Xuyên.

Bảng 1: Kết quả xử lý số liệu GPS chu kỳ 2007-2009

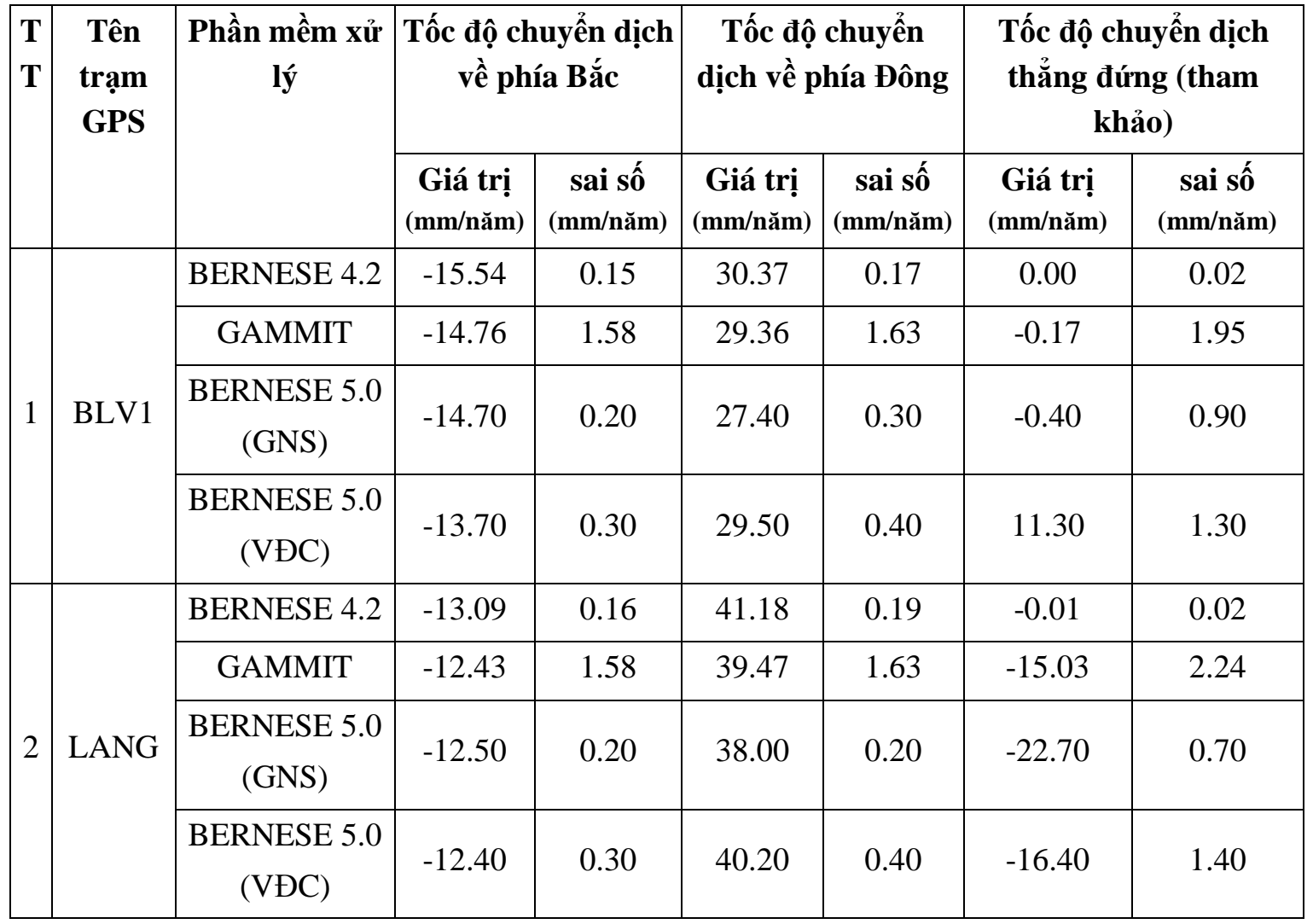




\begin{tabular}{|c|c|c|c|c|c|c|c|c|}
\hline \multirow{3}{*}{3} & \multirow{3}{*}{ DOHO } & BERNESE 4.2 & -7.68 & 0.17 & 28.21 & 0.20 & -0.01 & 0.03 \\
\hline & & GAMMIT & -10.26 & 1.60 & 26.79 & 1.68 & -2.19 & 2.45 \\
\hline & & $\begin{array}{c}\text { BERNESE } 5.0 \\
(\text { GNS })\end{array}$ & -9.10 & 0.30 & 24.60 & 0.40 & -15.20 & 1.50 \\
\hline \multirow{3}{*}{4} & \multirow{3}{*}{ HUES } & BERNESE 4.2 & -21.82 & 0.17 & 29.88 & 0.21 & 0.00 & 0.02 \\
\hline & & GAMMIT & -20.43 & 1.63 & 30.06 & 1.72 & 7.30 & 2.80 \\
\hline & & $\begin{array}{c}\text { BERNESE } 5.0 \\
(\text { GNS })\end{array}$ & -19.80 & 0.20 & 29.70 & 0.30 & 10.10 & 0.90 \\
\hline \multirow{4}{*}{5} & \multirow{4}{*}{ STT1 } & BERNESE 4.2 & -11.63 & 0.15 & 23.46 & 0.19 & 0.00 & 0.02 \\
\hline & & GAMMIT & -10.11 & 1.65 & 22.55 & 1.76 & -0.95 & 3.37 \\
\hline & & $\begin{array}{c}\text { BERNESE } 5.0 \\
\text { (GNS) }\end{array}$ & -10.30 & 0.30 & 21.60 & 0.30 & -7.60 & 1.30 \\
\hline & & $\begin{array}{c}\text { BERNESE } 5.0 \\
\text { (VĐC) }\end{array}$ & -11.60 & 0.30 & 23.10 & 0.40 & 6.30 & 1.40 \\
\hline \multirow{4}{*}{6} & \multirow{4}{*}{ CDA1 } & BERNESE 4.2 & -12.38 & 0.15 & 22.15 & 0.18 & 0.00 & 0.02 \\
\hline & & GAMMIT & -10.76 & 1.63 & 20.85 & 1.70 & -6.06 & 2.46 \\
\hline & & $\begin{array}{c}\text { BERNESE } 5.0 \\
\text { (GNS) }\end{array}$ & -7.40 & 0.20 & 20.40 & 0.30 & -9.70 & 1.00 \\
\hline & & $\begin{array}{c}\text { BERNESE } 5.0 \\
\text { (VĐC) }\end{array}$ & -9.80 & 0.30 & 21.30 & 0.40 & -7.20 & 1.50 \\
\hline \multirow{4}{*}{7} & \multirow{4}{*}{ HOCM } & BERNESE 4.2 & -11.24 & 0.17 & 22.83 & 0.21 & -0.01 & 0.03 \\
\hline & & GAMMIT & -13.46 & 1.65 & 21.50 & 1.76 & -4.64 & 3.07 \\
\hline & & $\begin{array}{c}\text { BERNESE } 5.0 \\
(\text { GNS })\end{array}$ & -11.50 & 0.20 & 21.70 & 0.30 & -3.10 & 1.00 \\
\hline & & $\begin{array}{c}\text { BERNESE } 5.0 \\
\text { (VĐC) }\end{array}$ & -13.20 & 0.30 & 20.90 & 0.50 & -1.20 & 1.50 \\
\hline
\end{tabular}

Đáng chú ý là kết quả của các nhà trắc địa của các nước Châu Á, Thái Bình Dương, "Permanent Committee for GIS Infrastructure for Asia and the Pacific" (PCGIAP) (Dawson và nnk, 2004). Hợp tác 11 nước trong đó có Úc, Newzeland, Hàn Quốc, Lào, Thái Lan, Việt Nam,... và cơ quan trắc địa Quốc tế IGS đã tiến hành đo tại 433 điểm từ 
1997, 1998, 1999, 2000, 2001, 2002. Phía Việt Nam tham gia đo 4 điểm tại Điện Biên, Đồ Sơn, Đà Nẵng và Vũng Tàu.

So với kết quả đo của Trung Quốc và các nước Châu Á và Thái Bình Dương, kết quả đo lặp của 3 kỳ đo trong khoảng thời gian 2007 - 2009 của chúng tôi là tương đối ngắn, tuy nhiên với sai số nhỏ nên giá trị chuyển dịch tuyệt đối hoàn toàn có ý nghĩa. Chúng ta đã có thể rút ra một số nhận xét về đặc điểm biến dạng của Biển Đông Việt Nam:

- Tiếp tục với xu thế chuyển dịch về phía Đông - Đông Nam đã quan sát thấy trên đất liền của Việt Nam, chúng ta quan sát thấy toàn bộ các trạm đo GPS đều chuyển dịch về phía Đông - Đông Nam. Kết quả trên cũng phù hợp với quan sát ở đảo Hải Nam, Quảng Tây, Quảng Đông cũng như toàn rìa Đông Nam Trung Quốc. Điều này cho thấy biến dạng trên Biển Đông Việt Nam chịu sự chi phối chủ yếu của đụng độ giữa mảng Ân Úc và mảng Âu Á.

- Sự suy giảm tốc độ chuyển dịch theo hướng từ Tây sang Đông của các trạm đo GPS phía Bắc (Láng, Bạch Long Vĩ, Hải Nam) cho thấy hiện nay vịnh Bắc bộ bị biến dạng nén và chịu xiết ép theo phương á vĩ tuyến hoặc lệch một chút về phía Đông Đông Nam. Trường lực này không thuận lợi cho hệ thống đứt gãy đang hoạt động tách dãn phương á kinh tuyến và cũng không thuận lợi cho các đứt gãy trượt bằng phương Tây Bắc - Đông Nam. Các hướng chính và giá trị chính của trục ứng suất - biến dạng sẽ được chúng tôi chính xác hoá ở các chu kỳ đo sau. Theo tính toán sơ bộ của chúng tôi, tốc độ biến dạng nén tính từ trạm Láng tới trạm Bạch Long Vĩ đạt giá trị xấp xỉ 10²/năm ( 10 nano biến dạng/năm).

- Phía Bắc Biển Đông đang đóng lại theo phương Tây Tây Bắc - Đông Đông Nam với tốc độ cỡ $77 \mathrm{~mm} / \mathrm{năm}$. Hướng của véc tơ chuyển dịch tại Láng, Bạch Long Vĩ, Hải Nam, Hoàng Sa hầu như ngược với hướng véc tơ chuyển dịch ở PIMO, phản ánh hướng chuyển dịch của mảng Bắc Biển Đông cắm dưới Philippine tại trũng Malina về phía Đông Đông Nam. Sự đóng lại của biển đông dọc theo đới cuốn chìm Manila có tốc độ không đều nhau phía Bắc đảo Luzon tốc độ chuyển dịch về phía Tây Bắc là lớn nhất sau giảm nhanh về phái Đông Nam. Điều đó chứng tỏ hoạt động của đới cuốn chìm Manila, ranh giới phía Đông Bắc của khối Sunda khá phức tạp. Đây là bằng chứng nói lên tính phân đoạn của đới cuốn chìm Manila.

- Các trạm đo GPS phía Nam (Song Tử Tây, Côn Đảo) có hướng chuyển dịch về phía Đông Nam cho thấy chế độ địa động lực ở phía Nam Biển Đông đã thay đổi so với phần phía Bắc Biển Đông, tốc độ chuyển dịch ngang nhỏ hơn ở phía Bắc. Biển Đông ở phần phía Nam không bị đóng lại. Tốc độ biến dạng nhỏ hơn phía Bắc Biển Đông. 


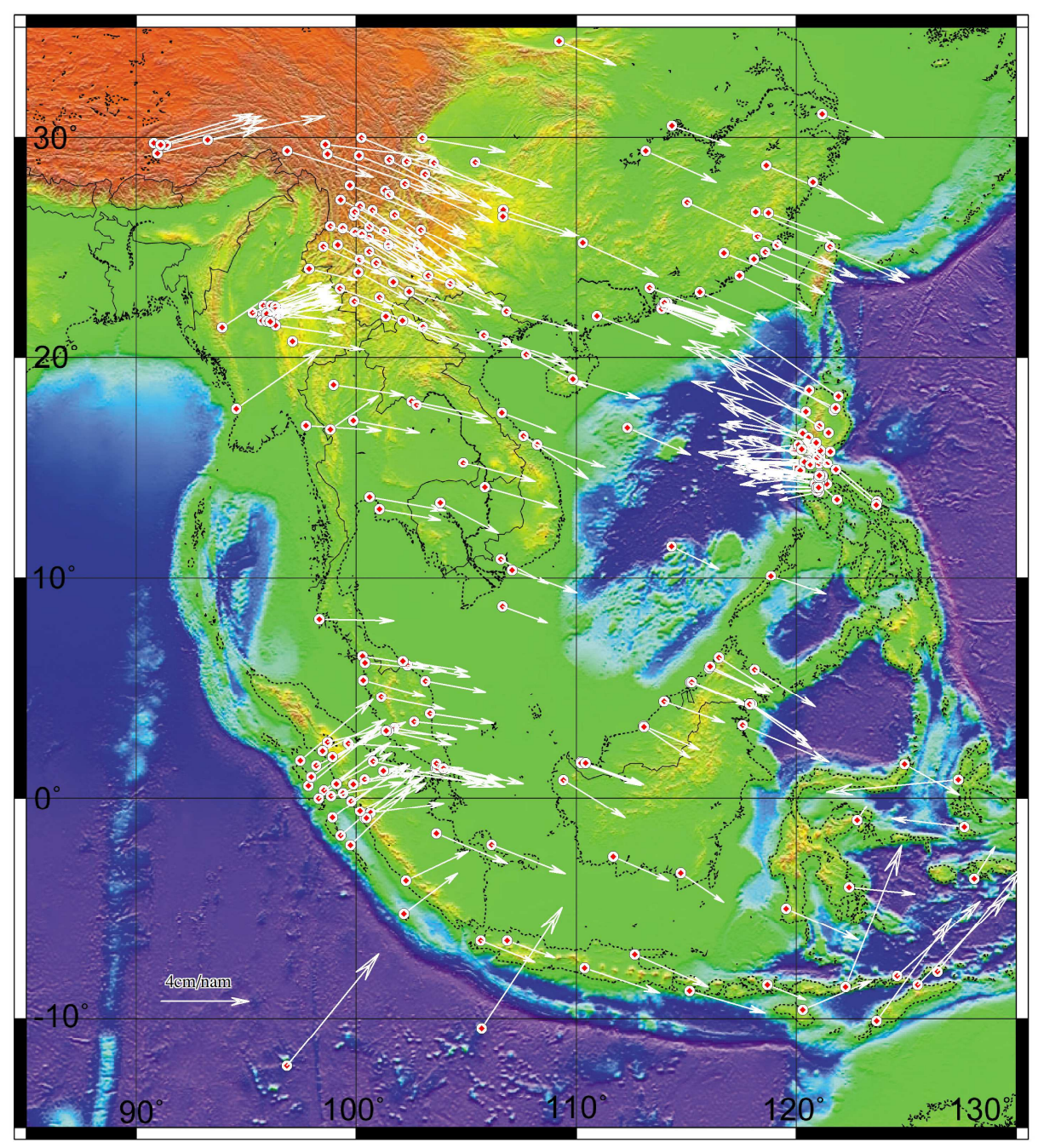

Hình 2: Sơ đồ tổng hợp các vec tơ vận tốc chuyển động kiến tạo hiện đại theo kết quả đo của chương trình GEODYSSEA, chương trình PCGIAP, chương trình SEAMERGES, chương trình CMONOC, Beavan và nnk., 2004, Bock và nnk., 2003, Chamote-Rooke, 1999, Dawson và nnk., 2004, Gan và nnk., 2007, Galgana và nnk., 2007, Iwakuni và nnk., 2004, Michel và nnk, 2001, Shen và nnk, 2005, Simos và nnk., 2007, Socquet và nnk, 2006, Rangin và nnk., 1999. Zhang và nnk, 2004 và kết quả đo GPS của tập thể tác giả bài báo này

- So sánh các vectơ chuyển dịch ở Thái Lan, Vũng Tàu, Malaysia và Palawan, thì vectơ chuyển dịch ở Côn Đảo và Song Tử Tây có nhỏ hơn và hơi lệch về phía Đông Nam. Nhìn chung, vùng Nam và Tây Nam Biển Đông hầu như không bị biến dạng lớn. Với kêt quả đo tại Côn Đảo, Hồ Chí Minh và Song Tử Tây, đối sánh với kết quả đo ở Palawan trong các đề án GEODYSSEA và PCGIAP thì không thấy sự xiết ép xảy ra ở Bắc Borneo. Kết quả này trái ngược với kết quả của (Simons, 2007). Khi cố định khối Sunda, Simons 
đã tính chuyển dịch tại một số trạm đo Bắc Borneo có hướng quay về Tây Bắc hoặc Tây Tây Bắc, từ đó tác giả giả định rằng có một phần ranh giới của khối Sunda đi qua rìa phía Bắc của Borneo. Theo chúng tôi ranh giới của khối Sunda dịch về phía Nam của Borneo vì thực tế có sự thay đổi rất lớn về tốc độ chuyển dịch tại đây, lớn hơn rất nhiều so với thay đổi tốc độ ở rìa Bắc Borneo với khối Sunda.

- So sánh các vectơ chuyển dịch tại DOHO, CDA1, STT1 thì có thể thấy biến dạng rất nhỏ, điều đó chúng tỏ nếu đứt gãy 110 đang hoạt động thì tốc độ chuyển dịch rất nhỏ. Chúng tôi sẽ chính xác hoá tốc độ tối đa của đới đứt gãy này trong những đợt đo tiếp theo.

- Biến dạng giữa các mảng và trong mảng ở Đông Nam Á được thể hiện như trên hình 2. Từ phân tích tốc độ tensơ biến dạng, có thể xác định được vùng có tốc độ biến dạng rất nhỏ dưới 7 nano biến dạng/năm, thể hiện vùng không biến dạng bên trong khối Sunda. Ranh giới được chính xác hoá và tóm tắt như sau: Về phía Tây, khối Sunda được bao bởi đứt gãy trượt bằng phải, xác đinh rõ ràng hướng của tenso biến dạng. Nó kéo dài từ Myanmar tới Sumatra dọc theo đứt gãy Sagaing, hệ thống pull-apart Andaman. Về phía Nam Java, khối bị giới hạn bởi máng nước sâu Java. Tuy nhiên vòng cung đảo Java chịu biến dạng rất lớn và gắn liền với động đất, gần đây vừa xảy ra trận động đất Yogakarta năm 2006. Nếu như đứt gãy đang hoạt động đó được khẳng định thì chỉ phần Tây của Java là thuộc về Sunda và đứt gãy rượt bằng, hướng về Đông Bắc được coi là của Sunda (hoặc thềm Sunda). Tốc độ biến dạng cao giữa Borneo và Sulawesi với mật độ GPS rất cao, theo chúng tôi ranh giới mảng Sunda sẽ đi qua đường phân cắt gữa Borneo và Sulawesi. Biến dạng tiếp tục tới rìa Đông giữa vĩ tuyến $10^{\circ} \mathrm{N}$ và $5^{\circ} \mathrm{N}$, Bắc Sulawesi, đới Philipin. Rìa đông của Sunda là 3 máng biển sâu vòng cung đảo Philipin Cotabato, Negros và trũng Manilla. Về phía Bắc, ranh giới của Sunda khó có thể xác định nhờ phân tích tốc độ biến dạng: Biển Đông hầu như không biến dạng và khối Nam Trung Hoa biến dạng rất yếu. Mặc dù trong khối Nam Trung Hoa, không có dấu hiệu biến dạng nhưng nó có ranh giới về phía Tây là đứt gãy Longmenshan và đứt gãy Xiaojiang. Dọc theo đới đứt gãy này, là một đới biến dạng mạnh gây ra do đụng độ giữa mảng Ấn Úc và mảng Âu Á. chuyển dịch từ Tây Tạng theo chiều kim đồng hồ, quanh Đông Hymalaya. Biến dạng này mở rộng sang Malaysia và thể hiện ở bắc Thái Lan bởi tách giãn Đông - Tây. Tốc độ biến dạng tăng cao ở Tây Bắc Thái Lan khẳng định ranh giới phía Bắc của Sunda nằm gần Myanmar. Về phía Đông Bắc, phần Tây Nam của đới đứt gãy Sông Hồng (Leloup và nnk, 1995), biến dạng tương thích với chuyển dịch trượt bằng phải. Tuy nhiên tốc độ biến dạng qua ranh giới mảng này rất nhỏ trong giai đoạn hiện tại. Tại điểm này, chỉ sử dụng phân tích biến dạng từ mạng lưới lớn rất khó có thể kết luận khối Nam Trung Hoa và Sunda có khác nhau về chuyển dịch hay không (Simons, 2007). 
- Chuyển dịch của khối Sunda cho thấy khá phù hợp với mô hình chuyển dịch khối, xảy ra chủ yếu dọc đới đứt gãy, thường gọi là mô hình thúc trượt (Extrusion) (Tapponnier và nnk, 1982) hơn là mô chảy nhớt và biến dạng liên tục (England và Houseman, 1986).

Trong bài viết này, chúng tôi chưa tính tốc độ xoay của Biển Đông do khoảng thời gian đo quá ngắn, tuy nhiên có thể tổng hợp tốc độ xoay của Biển Đông nói riêng và khối Sunda nói chung theo các tác giả khác nhau, được trình bày ở bảng 2 .

Bảng 2 : Các vector xoay tuyệt đối và tương đối của Biển Đông, Âu Á, Nam Trung Hoa theo các tác giả khác nhau (liệt kê trong bảng)

\begin{tabular}{|c|c|c|c|c|c|c|c|c|c|}
\hline \multirow[b]{2}{*}{ Tác giả } & \multirow[b]{2}{*}{ Hệ toạ độ } & \multirow{2}{*}{$\begin{array}{c}\text { Số } \\
\text { trạm } \\
\text { tính } \\
\text { toán } \\
\end{array}$} & \multicolumn{3}{|c|}{ Các tham số về xoay } & \multicolumn{4}{|c|}{ Sai số } \\
\hline & & & $\begin{array}{l}\text { Lat, } \\
\text { _N }\end{array}$ & $\begin{array}{c}\text { Lon, } \\
\text { _E }\end{array}$ & w_/triệu năm & smaj/lat & smin/lon & Azimuth & $\mathbf{X} 2$ \\
\hline \multicolumn{10}{|c|}{ Vec to' xoay tuyệt đối } \\
\hline \multicolumn{10}{|l|}{ Khối Sunda } \\
\hline Wilson et al. [1998] & ITRF94 & 12 & 31.8 & -46 & 0.28 & - & - & - & - \\
\hline Simons et al. [1999] & ITRF96 & 12 & 51 & -113 & 0.23 & - & - & - & - \\
\hline Michel et al. [2000]b & ITRF97 & 15 & 59.7 & -102.7 & $0.34 \pm 0.01$ & 2.9 & 3.9 & NA & - \\
\hline Michel et al. [2001] & ITRF97 & 10 & 56.0 & -102.7 & $0.339 \pm 0.007$ & - & - & - & - \\
\hline Simons et al. [2007] & ITRF00 & 28 & 49.0 & -94.2 & $0.336 \pm 0.007$ & 1.9 & 0.3 & 111 & 1.03 \\
\hline Sella et al. [2002] & ITRF97 & 2 & 38.9 & -86.9 & $0.393 \pm 0.062$ & 10.2 & 0.8 & 110 & 0.24 \\
\hline Kreemer et al. [2003] & NNR & 9 & 47.3 & -90.2 & $0.392 \pm 0.008$ & 1.9 & 0.5 & 109 & 3.11 \\
\hline Bock et al. [2003]b & ITRF00 & 16 & 49.8 & -95.9 & $0.320 \pm 0.010$ & 3.5 & 1.0 & 121 & 1.20 \\
\hline Prawiro et al. [2004] & ITRF00 & 2 & 32.6 & -86.8 & $0.462 \pm 0.064$ & 7.0 & 0.8 & 113 & 4.00 \\
\hline \multicolumn{10}{|c|}{ Khối Dưong Tủ (Nam Trung Hoa) } \\
\hline $\begin{array}{l}\text { Shen et al. [2004]c } \\
\text { Australian Plate }\end{array}$ & ITRF00 & 81 & 61.2 & -115.6 & $0.322 \pm 0.002$ & 1.4 & 0.1 & 134 & 1.04 \\
\hline Altamimi et al. [2002] & ITRF00 & 4 & 32.3 & 39.4 & $0.614 \pm 0.006$ & 0.7 & 0.8 & NA & - \\
\hline Beavan et al. [2002] & ITRF00 & 11 & 32.8 & 37.5 & $0.621 \pm 0.002$ & 0.4 & 0.1 & 161 & 1.08 \\
\hline Fernandes et al. [2003] & ITRF00 & 11 & 32.4 & 38.8 & $0.621 \pm 0.005$ & 15 & 0.5 & 151 & - \\
\hline Wallace et al. [2004] & ITRF00 & 11 & 32.0 & 39.1 & $0.621 \pm 0.003$ & 0.6 & 0.3 & 163 & - \\
\hline Wallace et al. [2004] & ITRF00 & 6 & 32.9 & 38.1 & $0.621 \pm 0.004$ & 0.9 & 0.3 & 151 & 1.01 \\
\hline \multicolumn{10}{|c|}{ Xoay tưo'ng đối } \\
\hline \multicolumn{10}{|l|}{ Sunda /Ầ Á } \\
\hline Simons et al. [2007] & $\begin{array}{c}\text { Calais et al. } \\
{[2003]}\end{array}$ & $28 / 15 d$ & 36.2 & -70.0 & $0.101 \pm 0.010$ & 5.8 & 2.2 & 78 & 1.02 \\
\hline \multicolumn{10}{|l|}{ Sunda/Úc } \\
\hline Simons et al. [2007] & $\begin{array}{l}\text { Simons et } \\
\text { al. [2007] }\end{array}$ & $28 / 6 \mathrm{~d}$ & -6.9 & -128.2 & $0.694 \pm 0.009$ & 1.2 & 0.5 & 14 & 1.03 \\
\hline \multicolumn{10}{|l|}{ Sunda/Dương Tür } \\
\hline Simons et al. [2007] & $\begin{array}{c}\text { Shen et al. } \\
\text { [2004] }\end{array}$ & $28 / 81 d$ & -17.1 & 57.2 & $0.099 \pm 0.015$ & 2.9 & 1.7 & 153 & 1.03 \\
\hline
\end{tabular}

\section{KẾT LUẬN}

Mặc dù mới chỉ qua 3 kỳ đo năm 2007 - 2008 - 2009, những nét cơ bản về chuyển dịch kiến tạo hiện đại trên Biển Đông đã được xác định với tốc độ đóng ở phía Bắc Biển Đông trong khoảng $80 \mathrm{~mm} / \mathrm{năm}$. Hoạt động xiết ép theo phương á vĩ tuyến ở khu vực Bắc 
Biển Đông sẽ cản trở chuyển dịch của các đứt gãy thuận có phương á kinh tuyến và đứt gãy trượt bằng phương Tây Bắc- Đông Nam. Vai trò của đụng độ giữa mảng Ấn Úc đối với mảng Âu Á đóng vai trò chủ đạo đối với biến dạng của Biển Đông. Hướng chuyển dịch thay đổi từ chuyển dịch theo hướng Đông Đông Nam ở phần phía Bắc Biển Đông chuyển sang hướng Đông Nam ở phần phía Nam Biển Đông. Biến dạng xiết ép giảm ở phần phía Nam Biển Đông. Đới cuốn chìm Bắc Borneo không còn hoạt động. Vùng Nam và Tây Nam tốc độ biến dạng khá nhỏ, điều này càng khẳng định nguy cơ động đất sóng thần lớn nhất trên Biển Đông là đứt gãy ứng với trũng Manilla - Philippin. Dấu hiệu hoạt động của đứt gãy rìa Tây Biển Đông không rõ ràng, nếu có thì tốc độ chuyển dịch rất nhỏ.

Bài viết này là kết quả của đề tài trọng điểm cấp nhà nước, nhiệm vụ bổ sung KC09.11BS/06-10 và hỗ trợ của đề tài nghiên cứu cơ bản mã số: 105.06.36.09.

\section{TÀI LIỆU THAM KHẢO}

1. Bakiiz H., J. Wang, and Y. Chen, 1999. A Regional GPS Network Solution fop Monitoring Deformations of the Southeastern Eurasian Plate; GPS Solutions, Vol. 2, No. 4: 44-55.

2. Becker M., E. Reinhart, Soeb Bin Nordin, D. Angermann, G. Michel, and C. Reigber, 2000. Improving the velocity field in South and South-East Asia: The third round of GEODYSSEA; Earth Planets Space, v. 52: 721-726.

3. Beavan, J., P. Tregoning, M. Bevis, T. Kato, and C. Meertens, 2002. Motion and rigidity of the Pacific Plate and implications for plate boundary deformation, J. Geophys. Res., 107(B10), 2261, doi:10.1029/ 2001JB000282.

4. Bock,Y., L. Prawirodirdjo, J. Genrich, C. Stevens, R. McCaffrey, C. Subarya, S. Puntodewo, and E. Calais, 2003. Crustal motion in Indonesia from Global Positioning System measurements, J. Geophys. Res., 108(B8), 2367, doi:10.1029/2001JB000324.

5. Chamote-Rooke, N., and X. L. Pichon, 1999, GPS determined eastward Sundaland motion with respect to Eurasia confirmed by earthquake slip vectors at Sunda and Philippine Trenches, Earth Planet. Sci. Lett., 173: 439-455.

6. Duquesnoy, T., O. Bellier, M. Sebrier, M. Kasser, C. Vigny, F. Ego, I. Baha, E. Putranto, and I. Effendi, 1999. Geodetic study of a seismic segment of the Great Sumatran Fault (Indonesia), Bull. Soc. Geol. France, 170(1): 25-30. 
7. England, P., and G. Houseman, 1986. Finite strain calculations of continental deformation: 2. Comparison with the India-Asia collision zone, J. Geophys. Res., 91(B3): 3664-3676.

8. Galgana G., M. Hamburger, R. McCaffrey, E. Corpuz, Q. Chen , 2007. Analysis of crustal deformation in Luzon, Philippines using geodetic observations and earthquake focal mechanisms, Tectonophysics 432 (2007): 63-87.

9. Gan W., Zhang P. , Shen Z. K., Niu Zh., Wang M. ,Wan Y., Zhou D., Cheng, 2007. Present-day crustal motion within the Tibetan Plateau inferred from GPS measurements, J. VOL. 112, B08416, doi:10.1029/2005JB004120

10. Iwakuni, M., T. Kato, H. Takiguchi, T. Nakaegawa, and M. Satomura, 2004. Crustal deformation in Thailand and tectonics of Indochina peninsula as seen from GPS observations, Geophys. Res. Lett., 31, L11612, doi:10.1029/2004GL020347.

11. King, R., F. Shen, B. Burchfiel, L. Royden, E. Wang, Z. Chen, Y. Liu, X. Zhang, J. Zhao, and Y. Li, 1997. Global Positioning System measurements from eastern Tibet and their implications for India/Eurasia intercontinental deformation, Geology, 25(2): 179-182.

12. Leloup, P., R. Lacassin, P. Tapponnier, U. Scharer, D. Zhong, X. Liu, L. Zhang, S. Ji, and Phan Trong Trinh, 1995. The Ailao Shan-Red River shear zone (Yunnan, China), Tertiary transform boundary of Indochina, Tectonophysics, 251(14): 3-84.

13. McCaffrey R., 1991. Slip vectors and stretching of the Sumatran fore arc, Geology, 19(9): 881-884.

14. McCaffrey, R., P. Zwick, Y. Bock, L. Prawirodirdjo, J. Genrich, C. Stevens, S. Puntodewo, and C. Subarya, 2000. Strain partitioning during oblique plate convergence in northern Sumatra: Geodetic and seismologic constraints and numerical modeling, J. Geophys. Res., 105(B12), 28,363-28,376.

15. Michel, G. W., M. Becker, D. Angermann, C. Reigber, and E. Reinhart, 2000. Crustal motion in E- and SE-Asia from GPS measurements, Earth Planets Space, 52(10): 713-720.

16. Michel, G., et al., 2001. Crustal motion and block behaviour in SE-Asia from GPS measurments, Earth Planet. Sci. Lett., 187: 239-244. 
17. Ngô Văn Liêm, Phan Trọng Trịnh, Nguyễn Tuấn Anh, Hoàng Quang Vinh, 2008. Ứng dụng công nghệ GPS trong việc xác định chuyển dịch kiến tạo hiện đại, biến dạng mặt đất và công trình, Địa Kỹ Thuật, Năm thứ 12, số 2

18. Niu Z., Wang M. et al., 2005. Contemporary velocity field of crustal movement of Chinese mainland from Global Positioning System measurments, Chinese Science Bulletin 50,1-3.

19. Phan Trọng Trịnh, Ngô Văn Liêm, Vy Quốc Hải, Trần Đình Tô, Nguyễn Văn Hướng, Hoàng Quang Vinh, Bùi Văn Thơm, Nguyễn Đăng Túc, Nguyễn Quang Xuyên, Vũ Tuấn Hùng, Nguyễn Huy Thịnh, Trần Quốc Hùng, Lê Minh Tùng, Đinh Văn Thế, Bùi Thị Thảo, Nguyễn Việt Tiến và Nguyễn Tuấn Anh, 2009, Kết quả ban đầu về tốc độ chuyển dịch kiến tạo hiện đại trên Biển Đông, Tạp chí Địa chất số: 310/1-2

20. Peltzer, G., and F. Saucier, 1996. Present-day kinematics of Asia derived from geologic fault rates, J. Geophys. Res., 101, 27,943-27,956.

21. Prawirodirdjo, L., and Y. Bock, 2004. Instantaneous global plate motion model from 12 years of continuous GPS observations, J. Geophys. Res., 109, B08405, doi:10. 1029/2003JB002944.

22. Prawirodirdjo, L., et al., 1997. Geodetic observations of interseismic strain segmentation at the Sumatra subduction zone, Geophys. Res. Lett., 24(21): 26012604.

23. Rangin, C., X. L. Pichon, S. Mazzotti, M. Pubellier, N. Chamot-Rooke, M. Aurelio, A. Walpersdorf, and R. Quebral, 1999. Plate convergence measured by GPS across the Sundaland/Philippine Sea plate deformed boundary: The Philippines and eastern Indonesia, Geophys. J. Int., 139: 296-316.

24. Replumaz, A., R. Lacassin, P. Tapponnier, and P. Leloup, 2001. Large river offsets and Plio-Quaternary dextral slip rate on the Red River fault (Yunnan, China), J. Geophys. Res., 106(B1): 819-836.

25. Shen, Z.-K., C. Zhao, A. Yin, Y. Li, D. D. Jackson, P. Fang, and D. Dong, 2000. Contemporary crustal deformation in east Asia constrained by Global Positioning System measurements, J. Geophys. Res., 105(5): 721-734.

26. Shen, Z. K., J. Lu, M. Wang, and R. Burgmann, 2005. Contemporary crustal deformation around the southeast borderland of the Tibetan Plateau, J. Geophys. Res., 110, B11409, doi:10.1029/2004JB003421. 
27. Simons, W. J. F., B. A. C. Ambrosius, R. Noomen, D. Angermann, P. Wilson, M. Becker, E. Reinhart, A. Walpersdorf, and C. Vigny, 1999. Observing plate motions in S. E. Asia: Geodetic results of the GEODYSSEA project, Geophys. Res. Lett., 26(14): 2081-2084.

28. Simons, W. J. F., A. Socquet, C. Vigny, B. A. C. Ambrosius, S. Haji Abu, Chaiwat Promthong, C. Subarya, D. A. Sarsito, S. Matheussen, P. Morgan, and W. Spakman, 2007. A decade of GPS in Southeast Asia: Resolving Sundaland motion and boundaries, J. Geophys. Res., VOL. 112, B06420, doi:10.1029/2005JB003868,

29. Socquet, A., W. Simons, C. Vigny, R. McCaffrey, C. Subarya, D. Sarsito, B. Ambrosius, and W. Spakman, 2006a. Microblock rotations and fault coupling in SE Asia triple junction (Sulawesi, Indonesia) from GPS and earthquake slip vector data, J. Geophys. Res., 111, B08409, doi:10.1029/2005JB003963.

30. Socquet, A., C. Vigny, N. Chamot-Rooke, W. Simons, C. Rangin, and B. Ambrosius, 2006b. India and Sunda plates motion and deformation along their boundary in Myanmar determined by GPS, J. Geophys. Res., 111, B05406, doi:10.1029/2005JB003877.

31. Tapponnier, P., G. Peltzer, A. Y. Ledain, R. Armijo, and P. Cobbold, 1982. Propagating extrusion tectonics in Asia-New insights from simple experiments with plasticine, Geology, 10(12): 611-616.

32. Trần Đình Tô, Nguyễn Trọng Yêm, 2004. Chuyển động hiện đại vỏ Trái đất lãnh thổ Việt Nam theo số liệu đo GPS. Tạp chí các khoa học về Trái đất; 26(4),12/2004, tr.579-586, Hà Nội.

33. Vigny, C., A. Socquet, C. Rangin, N. Chamot-Rooke, M. Pubellier, M.-N. Bouin, G. Bertrand, and M. Becker, 2003. Present day crustal deformation around Sagaing Fault, Myanmar, J. Geophys. Res., 108(B11), 2533, doi:10.1029/2002JB001999.

34. Vigny, C., et al., 2005. Insight into the 2004 Sumatra-Andaman earthquake from GPS measurements in southeast Asia, Nature, 436, 201-206, doi:10.1038/nature03937.

35. Vy Quốc Hải, 2004. So sánh kết quả xử lý số liệu GPS của lưới địa động lực bằng phần mềm GPSurvey 2.35 và Bernese 4.2. Tạp chí các khoa học về Trái đất26(4),12/2004, tr.418-425, Hà Nội. 
36. Vy Quốc Hải, 2007. Kết quả bước đầu xác định chuyển động vỏ Trái đất bằng số liệu GPS vùng lân cận chấn tâm động đất Sumatra ngày 26/12/2004. Tạp chí Địa chất; loạt A, số 302, 9-10/2007, tr.1-9.

37. Wang, Q., et al., 2001. Present-day crustal deformation in China constrained by Global Positioning System measurements, Science, 294: 574-577.

38. Zhang, P., Z. Shen, M. Wang, W. Gan, R. Burgmann, P. Molnar, Q. Wang, Z. Niu, J. Sun, J. Wu, H. Sun, and X. You (2004). Continuous deformation of the Tibetan Plateau from Global Positioning System data, Geology, 32: 809-812.

\title{
VELOCITY OF ACTUAL TECTONIC MOVEMENT IN EAST VIETNAM SEA AND SURROUNDING FROM GPS MEASUREMENT 2007 - 2009
}

\author{
PHAN TRONG TRINH, NGO VAN LIEM, TRAN DINH TO, VY QUOC HAI, \\ NGUYEN VAN HUONG, HOANG QUANG VINH, BUI VAN THOM, NGUYEN QUANG XUYEN, \\ NGUYEN VIET THUAN, BUI THI THAO, LE HUY MINH, JOHN BEAVAN
}

\begin{abstract}
Summary: This paper presents new result of present day tectonic movement on the East Vietnam Sea and synthetics of GPS measurements from various authors in period from 1994 - 2009. In particular, the data from project of GEODYSSEA, China, service of AsiaPacific and the data from GPS campain 2007 -2009 of the project KC09.11/06-10. GPS stations Lang (LANG), Bach Long Vi (BLV1), Song Tu Tay (STT1), Con Dao (CDA1) are associated with IGS stations of the International GPS service like COCO, BAKO, NTUS, PIMO, KUNM and WUHN. We determine finally absolute displacements and velocities of these GPS stations in the IGS05. The result indicates that LANG moves eastward with slip rate of $\sim 39 \mathrm{~mm} / \mathrm{yr}$, southward with slip rate of $\sim 13 \mathrm{~mm} / \mathrm{yr}$. The rate of BLV1 is $\sim 29 \mathrm{~mm} / \mathrm{yr}$ for the eastern component and $\sim 14 \mathrm{~mm} / \mathrm{yr}$ for southern component. STT1 moves eastwards with the rate of $\sim 22,5 \mathrm{~mm} / \mathrm{yr}$ and southwards of $10,5 \mathrm{~mm} / \mathrm{yr}$. CDAl move to the east with the rate of $\sim 21 \mathrm{~mm} / \mathrm{yr}$ and to the south with the rate of $10 \mathrm{~mm} / \mathrm{yr}$. DOHO move to the east with the rate of $\sim 26,8 \mathrm{~mm} / \mathrm{yr}$ and to the south with the rate of $\sim 9 \mathrm{~mm} / \mathrm{yr}$. HUES move to the east with the rate of $\sim 30 \mathrm{~mm} / \mathrm{yr}$ and to the south with the rate of $\sim 20 \mathrm{~mm} / \mathrm{yr}$. HOCM move to the east with the rate of $\sim 21,5 \mathrm{~mm} / \mathrm{yr}$ and to the south with the rate of $\sim 12 \mathrm{~mm} / \mathrm{yr}$. Calculate errors for both direction vary in 0,5-0,6 $\mathrm{mm} / \mathrm{y}$.
\end{abstract}

Ngày nhận bài: 20 - 6 - 2010

Ngưòi nhận xét: TS. Phùng Văn Phách 